\title{
Mid-life predictors of late-life depressive symptoms; determining risk factors spanning two decades in the Women's Heathy Ageing Project
}

\author{
Katherine E. Campbell ${ }^{1,2^{*}}$, Alexandra Gorelik ${ }^{2,3}$, Cassandra E. Szoeke $e^{1,2,3^{*}}$ and Lorraine Dennerstein ${ }^{4}$
}

\begin{abstract}
Background: Data available from longitudinal studies of adequate duration to explore midlife risk factors for late life higher depressive symptom scores in women is lacking. This study examines midlife (mean ages 50 years and 60 years) predictors of late life (mean age 70 years) depressive symptom scores to enrich our understanding of the role of changing risk factors across the lifespan.

Methods: This investigation was an assessment of the long-term impact of lifestyle and health variables on depressive symptoms. Data were drawn from an epidemiological prospective study of women's healthy ageing spanning two decades. Variables included assessment of mood, demographics, physical health, smoking status, attitudes towards ageing and menopause, alcohol consumption and employment. Analysis was conducted to determine the set of strongest predictors assessed in 1992 (mean age 50 years) and in 2002 (mean age 60 years) in relation to higher CESD-SF scores measured in 2012 (mean aged 70 years $(n=249)$ ). A cross-sectional analysis determining concurrent associations at mean age 70 years was also conducted.

Results: An increase in positive mood at 50 and 60 years was associated with a $0.3(95 \% \mathrm{Cl} 0.1-0.5)$ and $0.4(95 \% \mathrm{Cl}$ $0.1-0.8)$ point reduction in CESD score at 70 years respectively. An increase in Hassles score at age 50 was associated with a 0.18-point increase in CESD $(95 \% \mathrm{Cl} 0.01-0.05) 20$ years later. However, no relationship was observed between Hassles score at 60 and CESD 10 years later. Analysis of concurrent risk factors demonstrated that bothersome symptom frequency and higher anxiety were associated with higher depressive symptom scores when women were 70 years.

Conclusion: Low levels of positive mood were consistently associated with depressive symptoms scores 10 and 20 years later, suggesting clinical interventions aimed at improving positive affect may be particularly useful across the midlife.
\end{abstract}

Keywords: Late life, Mid-life, Depressive symptoms, CESD, Hassles, Affectometer-2, WHAP

\footnotetext{
* Correspondence: katherine.campbell@unimelb.edu.au;

cszoeke@unimelb.edu.au

'School of Psychology, Charles Sturt University, Bathurst, New South Wales,

Australia

Full list of author information is available at the end of the article
}

(c) The Author(s). 2020 Open Access This article is distributed under the terms of the Creative Commons Attribution 4.0 International License (http://creativecommons.org/licenses/by/4.0/), which permits unrestricted use, distribution, and reproduction in any medium, provided you give appropriate credit to the original author(s) and the source, provide a link to the Creative Commons license, and indicate if changes were made. The Creative Commons Public Domain Dedication waiver (http://creativecommons.org/publicdomain/zero/1.0/) applies to the data made available in this article, unless otherwise stated. 


\section{Background}

Mid-life, commonly defined as 45-65 years, represents a time of significant physiological and psychological change for women [1]. With the onset of early postmenopause, severe vasomotor symptoms are more likely to occur [1]. These are also known to be associated with higher reporting of depressive symptoms [2]. In addition to the onset of menopause, other life changes that may be associated with mood fluctuations are common to mid-life women [3]. These include; changes in professional role and work commitments, the onset of physical or health problems, additional responsibility to care for ageing parents, and changes in relationships and sexual functioning $[4,5]$. While risk factors associated with higher depressive symptom scores at certain age ranges in women are well documented $[5,6]$, less is known about the long-term impact of psychological and lifestyle factors experienced during the transition from midlife to late life. Identifying midlife risk factors amenable to behavioural and psychological intervention has the potential to inform the types of clinical intervention used with midlife women who are at risk of later developing depressive symptoms. There is growing consensus that midlife predictors of late life illness are important to mitigate the impact of negative symptoms in old age.

Longitudinal studies spanning the stages of reproductive ageing, with frequent points of assessment, provide the best means for exploring the changing risk factors for women transitioning from midlife to late life. The Women's Healthy Ageing Project (WHAP), a longitudinal study of women's healthy ageing, found that risk factors assessed when women were of an average age of 50 years predicted higher depressive symptom scores a decade later [7]. These predictors included: negative attitudes towards ageing; negative attitudes towards menopause; negative mood scores; and prior premenstrual complaints. Another study of longitudinal aging, The Study of Women's Health Across the Nation (SWAN), examined baseline predictors assessed when women were of mean age 47 years in those who developed Major Depressive Disorder (MDD) by the final assessment point when women were of average age 60 years [8]. These researchers found that the baseline characteristics associated with presence of later MDD included: higher mean trait anxiety, higher mean private selfconsciousness, lower mean optimism, higher percentage of lifetime anxiety disorder, two or more lifetime medical conditions, and past use of psychotropic medication [8]. In another study the SWAN team examined the association between physical activity and depression in 2891 women who provided data over 10 years, mean age 42 years at baseline [9]. The findings demonstrated that higher levels of physical activity were associated with lower levels of depressive symptoms persistently over 10 years.

In an examination of factors at the nine-year follow up point in the Penn Ovarian Ageing Study, higher levels of stress at baseline were associated with higher selfreported depressed mood [10]. Across an eight-year follow up, hot flashes, BMI, smoking status, PMS, employment, and marital status were identified as significant risk factors for high CES-D scores [11]. In 2017 Mitchell and Woods published a summary of the factors associated with depressed mood in the Seattle Midlife Women's Health Study across 13 years of follow up (baseline mean age 41 years) [12]. Individual models, using age as the measure of time, showed that the following variables were associated with higher depressed mood severity: greater perceived stress, having a history of sexual abuse, difficulty getting to sleep, early awakening, and awakening at night [12]. Factors associated with lower depressed mood included: being postmenopausal, exercising more, and having a partner [12].

In this study midlife predictors of late-life depressive symptoms were explored by analysing 20 years of longitudinal prospective data. Depressive symptoms were explored in order to capture more sensitive differences in symptom reporting than could be determined using a categorical diagnosis of presence or absence of Major Depressive Disorder. Using depressive symptom measures rather than clinical diagnosis can also be particularly relevant to this cohort given that older adults are less likely to be diagnosed with a major depressive disorder but are more likely to report more depressive symptoms than their middle-aged counterparts [13]. The purpose of this study was to extend earlier research examining the impact of mid-life variables on depressive symptoms across a 10-year timespan of the WHAP cohort. The duration of the WHAP study now allows for an assessment of the impact of mid-life variables on level of depressive symptoms over a 20-year time frame, providing an opportunity to explore the long-term impact of lifestyle and psychological variables on depressive symptoms. The multiple points of assessment also allow for an examination of the changing risk factors associated with higher depressive symptoms at different life stages. While the previous examination of the WHAP cohort focused on the development of risk factors within the context of reproductive aging, this research examines the variables in the context of chronological ageing, a more relevant context given the age of the cohort.

In this paper we examined lifestyle and health variables associated with early late life higher depressive symptom scores at mean age 70 years. The goal of this analysis was to determine whether risk factors identified when women were aged 50 and 60 remained consistent or represented unique, age specific risk factors. The 
specific goals of the research were; 1) to assess the association between specific lifestyle and health variables assessed at age 70 in relation to higher depressive symptom scores at age 70 as part of a cross-sectional analysis, 2) to assess the association between specific lifestyle and health variables assessed at age 60 in relation to higher depressive symptom scores at age 70 in order to determine which factors may impact higher depressive symptom scores 10 years later, and, 3) to assess the association between specific lifestyle and health variables assessed at age 50 in relation to higher depressive symptom scores at age 70 in order to determine which factors may impact higher depressive symptom scores 20 years later. Understanding consistent and age specific risk factors predictive of later depressive symptoms would contribute to the understanding of potential modifiable risk factors present during the span of the midlife.

\section{Method \\ Participants \\ Women's healthy ageing project baseline cohort (1992- 2002)}

Participants who contributed data to this study were part of the Women's Healthy Ageing Project (WHAP), an ongoing longitudinal epidemiological study initially known as the Melbourne Women's Midlife Health Project (MWMHP). The study was originally established to describe Australian women's experience of the menopausal transition as well as the health and lifestyle factors associated with their experience of the climacteric. As the study continued, additional variables were introduced to explore research questions relevant to the ageing cohort. The women were Australian born Melbourne residents, aged between 45 and 55 years when they were originally contacted by random digit dialling [14]. Sample size at baseline (1992) was 438 , with retention remaining high at year 8 of follow-up (88\%). A more detailed summary of the cohort and procedure has been described in Dennerstein et al., 2004 [7].

\section{Women's healthy ageing project follow-up cohort (2002-2012)}

Assessments were conducted annually between 1991 and 1999, then were readministered in 2002, 2004 and 2012. A more detailed summary of the cohort and procedures, including the 2002 and 2012 assessment points, has been described in Szoeke et al., 2016 [14]. At the 20year follow-up, 53\% of the cohort assessed in 1992 returned for assessment $[14,15]$. At each point of contact the study has been approved by the Human Research Ethics Committee of the University of Melbourne. All procedures and ethical standards are in accordance with those outlined by the National Health and Medical Research Council. All women have provided written consent for each time point in which they have participated.

\section{Measures \\ Centre for Epidemiological Depression Scale (CESD) short form}

The CESD-SF is a 10-item, self-report scale used to assess the presence and severity of depressive symptoms in the general population. The measure was introduced into the assessment protocol in 2002. The CESD-SF has been shown to have high reliability (test retest reliability, $\mathrm{r}=0.71$ ) and good predictive accuracy when compared to the full 20 item CESD [16]. Scores range from 0 to 30 and have a cut off range of $<10$ to categorise normal versus mild to moderate symptoms $[17,18]$. A score of 10 or greater is used to categorise an individual as having severe enough levels of depressive symptoms to potentially be diagnosed as clinically depressed [19]. Higher scores on the CESD represent higher levels of depressive symptoms [17].

\section{The hospital anxiety and depression scale (HADS)}

The HADS is a 14 item self-assessment scale used to assess states of depression and anxiety [20]. Participants rate how much they had been experiencing the emotional state represented by the item during the last week on a scale of $0-3$ (with 3 reflecting higher rates). Separate depression (HADS-D) and anxiety (HADS-A) subscales are derived from 7 specific items related to these states. Scores for each of the subscales range from 0 to 21. Sensitivity and specificity for both HADS-A and HADS-D is approximately 0.80, and correlations with other commonly used questionnaires of this nature (such as the Beck Depression Inventory) range between 0.49 to 0.83 [21].

\section{Affectometer 2- negative mood, positive mood, wellbeing}

The Affectometer 2 is a measure that assesses negative mood, positive mood and wellbeing by asking participants to rate how much they had felt an experience in the past week. Items included 20 adjectives (10 positive and 10 negative) rated on a four-point scale from "most of the time" [3] to "hardly ever" (0) [22]. The mean sum of the scores for the negative adjectives were used to determine the "Negative Mood" score and the positive items were used to determine "Positive Mood". The "Wellbeing" score was calculated as the difference between the two mood scores [7]. Higher scores represent higher levels of experience for both positive and negative scales [7]. 


\section{The hassles scale}

The Hassles Scale is a measure of chronic stress. The scale includes 23 items representing daily "hassles" which were selected and rated as 'somewhat severe', 'moderately severe' or 'extremely severe' to provide a total 'hassles severity score' [16]. Daily hassles represent minor negative experiences that occur on a regular basis and are perceived as threatening, irritating, frustrating or distressing [23]. The cumulative nature of these experiences represents ongoing, chronic levels of stress.

\section{Attitudes towards ageing}

Attitudes towards ageing was assessed using six items rated on a three-point Likert scale to provide a total positive score [24, 25]. A positive response was taken to indicate an overall higher/more positive attitude towards ageing.

\section{Attitude to menopause}

Seven items consisting of statements related to menopause were rated as 'strongly agree'; 'agree'; 'disagree' or 'strongly disagree' to determine an overall score of attitude to menopause [25-27]. Positive scores were totalled to derive an overall total score, with higher total representing overall higher/more positive attitude towards menopause.

\section{Demographic variables}

Data relating to age, education (categorized as 0-12 years or greater than 12 years), marital status (categorized as married/defacto or single/divorced) and work status (currently employed or not currently employed) were included in this analysis. The categories used were selected based on those previously used in the published WHAP analyses. For marital status and education subcategories were collapsed into two larger categories for more meaningful analysis.

\section{Lifestyle variables}

A number of lifestyle variables were assessed (see [28] for a detailed overview of the variables used in the WHAP). Lifestyle variables used in this analysis included: current smoker (yes/no); exercise for fitness or recreation at least once a week (yes/no); and 'current drinker' determined by consumption of alcohol in the last week (yes/no). These groups were categorized based on available data across the study where categories of responses changed over time. The most consistent way to represent alcohol based on different response categories was to identify those that had consumed alcohol in the last week compared to those who had not.

\section{Physical activity}

A measure of physical activity was introduced in 1993 and has been assessed at each subsequent time point. Participants were asked to rate their level of physical activity. Categories used in this analysis included "often" (4-6 times per week or daily); "regularly" (1-3 times a week), or; "rarely" (<once a month or never).

\section{Self-rated health}

Participants were asked to rate their health as 'worse', 'the same' or, 'better than' their peers [24]. This was a subjective measure introduced when the study began to compliment other variables associated with attitude towards ageing and attitude towards menopause [7].

\section{Bothersome symptoms}

A list of 22 symptoms commonly experienced during the climacteric were categorized by participants as either 'yes this symptom has bothered me' or 'no it has not' [16]. Items included physical symptoms such as: dizzy spells, lack of energy, backaches, difficulty swallowing we well as feeling sad or downhearted. The overall number of bothersome symptoms experienced by the participant provided a total score.

\section{Additional health variables}

Participants also provided data regarding the presence of a chronic condition (diabetes, asthma, allergies or eczema, hypertension, heart disease, stomach or bowel ulcers, arthritis or rheumatism, cancer, or migraine), current use of prescription medication, and problematic premenstrual changes. Both height and weight were assessed by a trained researcher at each site visit. Participants were asked to remove shoes and heavy clothes prior to this assessment. The height was measured with stadiometer to the closest $0.01 \mathrm{~m}$ and weight was measured using digital scale (pre-stabilised) to the nearest $0.1 \mathrm{~kg}$. Body Mass Index BMI $(\mathrm{kg} / \mathrm{m} 2)$ was then calculated using standard equation. Menopausal status was also assessed and categorized using the updated STRAW+ 10 criteria [1]. The date of the final menstrual period (FMP) was recorded by participants in their menstrual diaries and was used to determine menopausal stage.

\section{Statistical analysis}

All continuous variables were tested for normality using Shapiro-Wilk's test, prior to data analysis. Spearman correlation and Mann-Whitney U-test were used to assess any associations between CESD and participants' demographic and clinical data. Differences between groups were assessed using either Student T-test or MannWhitney U-test for continuous data and either Chisquared or Fisher's exact test for categorical data as 
appropriate. Multivariable gamma regression (with log link) was used to determine the impact of variables assessed in 1992, 2002 and 2012 on primary outcome (CESD-SF score at age 70), while controlling for potential confounders. All models were adjusted for age, BMI, work status, positive affect, marital status and self-rated health as these were consistent between all-time points and were also identified as potential confounders. Certain variables included as predictors were assessed only at a single time-point. Specific variables used at each assessment point are detailed in the corresponding results section. Following gamma regression, the marginal effects were calculated, and results reported in the text refer to the predicted values. All analyses were conducted using SPSS (Statistical Package for Social Science) 18 [29] and STATA15 software [30] with $p<0.05$ considered statistically significant.

\section{Results \\ Concurrent variables associated with higher late life scores (2012)}

A total of 249 women (56.8\%) of the original cohort assessed in 1992 provided data in 2012. The mean age of the women in this study was 69.8 years (SD 2.57) and the mean score for CESD-SF was 5.20 (SD 4.27). A description of the variables assessed in 2012 is included in Table 1.

Participants who provided data in 2012, but who were not included in the analysis due to missing items on the CESD $(n=29)$, were significantly more likely to have scored lower on the HADS-D scale $(p=0.020)$ than those included in the analysis. Based on bivariate analysis, smokers had significantly higher CESD score (7 $(4-11)$ vs $(4,(2-7)$ for non-smokers, $(p=0.042)$, and higher scores compared to those employed ( 5 (2-8) vs 4 $(1-7), p=0.039)$. Women who self-rated their health as "better than most" had significantly lower CESD compared to others $(4(1-6)$ vs $6(3-9), p=0.014)$. The results also show moderate correlation between CESD and negative $\operatorname{mood}($ rho $=0.6, p<0.001$ ), positive $\operatorname{mood}$ (rho $=0.6-0.5, p<0.001$ ), wellbeing (rho $=0.6, p<0.001$ ), GDS score (rho $=0.6, p<0.001$ ), HADS-A and HADS-D score (rho $=0.6, p<0.001$ for both), number of hassles (rho $=0.4, p<0.001$ ) and number of bothersome symptoms (rho $=0.5, p<0.001$ ). Based on bivariate analysis, variables associated with higher CESD scores included: smoking status $(p=0.042)$, self-rated health $(p=0.014)$, work status $(p=0.039)$, negative $\operatorname{mood}(p<0.001)$, positive mood ( $\mathrm{p}<0.001)$, wellbeing $(p<0.001)$, GDS score $(p<0.001)$, HADS-A score $(p<0.001)$, HADS-D score $(p<0.001)$, number of hassles and number of bothersome symptoms. Refer to Appendix 1 in Table 7 for a summary of these analyses.
However, the results of multivariate analysis showed that bothersome symptom frequency and higher anxiety as measured by the HADS-A only were statistically significantly associated with higher CESD-SF scores (Table 2).

Analysis was adjusted for age, education, marital status, smoking status, physical activity, employment, and BMI, none of which showed significance. The results of the analysis indicated that higher scores of bothersome symptoms were associated with a $0.26(p=0.019)$ point increase in CESD-SF scores while higher scores on the HADS anxiety measure were associated with a 0.45 $(p=0.005)$ increase in CESD-SF score.

Ten year predictors of higher late life scores (2002-2012) A total of 257 women (58.7\%) of the original cohort assessed in 1992 provided data in 2002. Of those women 162 had scores for CESD-SF in 2012 in addition to required variables assessed in 2002. The mean age of the women included in the sample used in this study was 59.8 years (SD 2.5) and the mean score for CESD-SF was 6.7 (SD 4.0). A description of characteristics, as well as differences between those included in the 2012 cohort and those who dropped out prior to 2012 are included in Table 3.

There were no significant differences in lifestyle, health or mood variables between participants who dropped out of the study between 2002 and the 2012 assessment, and those who continued $(n=162)$.

Analysis of associations between individual 2002 factors and 2012 CESD scores demonstrated mild to moderate correlation between 2012 CESD scores and the following variables assessed in 2002: CESD-Brief score (rho $=0.3, p=<0.001)$; negative $\operatorname{mood}($ rho $=0.3, p=<$ 0.001 ); positive $\operatorname{mood}($ rho $=-0.4, p<0.001$ ); wellbeing score (rho $=0.4, \quad p<0.001$ ); number of bothersome symptoms (rho $=0.3, p=<0.001$ ) and number of daily hassles (rho $=0.3, p<0.001$ ). However, positive mood remained the only predictor of CESD score 10 years later, while controlling for potential confounders. See Appendix 2 in Table 8 for a summary of the analyses.

The results of the analysis indicated that lower scores on the positive mood scale was a statistically significant predictor of higher CESD scores in 2012 (Table 4). A higher positive mood score resulted in a 2.50 point decrease in CESD total severity $(p=0.007)$.

\section{Twenty year predictors of higher late life scores (1992-2012)}

A total of 220 women (50.23\%) who provided data in 1992 had scores for CESD-SF in 2012 in addition to required variables assessed in 1992 used in the multivariate analysis. The mean age of the women included in the sample used in this study was 49.63 years (SD 2.53) and the mean score for CESD-SF was 5.20 (SD 4.271). A 
Table 1 Description of means scores for variables assessed in 2012

\begin{tabular}{|c|c|c|}
\hline 2012 Variables & Overall Cohort 2012 & Range \\
\hline Sample Size & 249 & \\
\hline Age Mean (SD) & $69.8(2.6)$ & $64.9-77.3$ \\
\hline \multicolumn{3}{|l|}{ Affectometer Score } \\
\hline Negative Mood Score Mean (SD) & $3.7(0.34)$ & $1.60-4$ \\
\hline Positive Mood Score Mean (SD) & $1.3(0.5)$ & $0.9-3.1$ \\
\hline Wellbeing Score Mean (SD) & $2.3(0.8)$ & $1.1-3.1$ \\
\hline \multicolumn{3}{|l|}{ Hospital Anxiety Stress Scale } \\
\hline Anxiety Subscale & $4.9(3.5)$ & $0-17$ \\
\hline Depression Subscale & $2.4(2.2)$ & $0-12$ \\
\hline \multicolumn{3}{|l|}{ Education } \\
\hline $0-12$ years & $119(58.6)$ & \\
\hline $12+$ years & $84(41.4)$ & \\
\hline \multicolumn{3}{|l|}{ Marital Status } \\
\hline Married/Defacto & $154(67.05)$ & \\
\hline Single/Divorced & $76(33.0)$ & \\
\hline \multicolumn{3}{|l|}{ Physical Activity } \\
\hline Rarely $n$ (valid \%) & $59(25.4)$ & \\
\hline Sometimes $n$ (valid \%) & $72(31.1)$ & \\
\hline Often $n$ (valid \%) & $101(43.5)$ & \\
\hline Daily Hassles Severity Mean (SD) & $4.9(8.5)$ & \\
\hline Bothersome Symptoms Frequency Mean (SD) & $5.7(4.2)$ & \\
\hline \multicolumn{3}{|l|}{ Work Status n (valid \%) } \\
\hline Not employed & $166(78.7)$ & \\
\hline Employed & $44(20.9)$ & \\
\hline \multicolumn{3}{|l|}{ Self-Rated Health Status $n$ (valid \%) } \\
\hline 'Same as/worse than most' & $104(50.5)$ & \\
\hline 'Better than most' & $91(19.4)$ & \\
\hline \multicolumn{3}{|l|}{ Smoking Status } \\
\hline Smoker & $15(7.1)$ & \\
\hline Non-smoker & $197(92.9)$ & \\
\hline BMI Mean (SD) & $28.1(5.4)$ & $18.3-54.2$ \\
\hline
\end{tabular}

SD standard deviation

Table 2 Multivariate analysis of lifestyle and health variables and CESD scores from 2012

\begin{tabular}{lll}
\hline Variable & Beta $(95 \% \mathrm{Cl})$ & $p$-value \\
\hline Positive Mood Score & $-0.24(-0.55,0.87)$ & 0.152 \\
Bothersome Symptoms Frequency & $0.04(0.01,0.08)$ & $\mathbf{0 . 0 1 5}$ \\
Daily Hassles Severity & $0.00(-0.01,0.02)$ & 0.774 \\
HADS-A Total & $0.08(0.03,0.13)$ & $\mathbf{0 . 0 0 3}$ \\
HADS-D Total & $0.03(-0.04,0.15)$ & 0.351
\end{tabular}

$\mathrm{Cl}$ Confidence Intervals, bold, italicised - significant; Gamma regression was used to derive estimates description of characteristics, as well as differences between those included in the 2012 cohort and those who dropped out prior to 2012 is included in Table 5.

Participants who dropped out of the study prior to the 2012 assessment were more likely at the 1992 assessment point to have; a higher number of premenstrual complaints $(p=0.041)$; report more daily hassles $(p=0.012)$; to rate their health as the same or worse than other woman their age $(p=0.013)$; have completed between 13 and 15 years of education $p=$ - 0.024); to smoke $(p=0.049)$; and to report lowered $\operatorname{mood}(p=0.029)$.

Analysis of association between individual 1992 factors and 2012 CESD scores demonstrated mild to moderate 
Table 3 Summary of 2002 cohort and comparison of those who completed 2012 follow-up and those who did not

\begin{tabular}{|c|c|c|c|c|}
\hline & Variable 2002 & Included in 2012 follow-up assessment & Did not have follow-up data 2012 & $p$-value \\
\hline Sample Size & 257 & 162 & 95 & \\
\hline Age & $59.8(2.5)$ & $59.8(2.5)$ & $59.9(2.5)$ & $\wedge 0.550$ \\
\hline \multicolumn{5}{|l|}{ Affectometer Score } \\
\hline Negative Mood Score & $0.3(0.3)$ & $0.3(0.3)$ & $0.4(0.3)$ & $\wedge 0.257$ \\
\hline Positive Mood Score & $2.2(0.6)$ & $2.2(0.6)$ & $2.2(0.6)$ & $\wedge 0.783$ \\
\hline Wellbeing Score & $1.9(0.8)$ & $1.9(0.8)$ & $1.8(0.9)$ & $\wedge 0.521$ \\
\hline CESD-Brief & $6.8(4.1)$ & $6.7(4.0)$ & $6.8(4.3)$ & $\wedge 0.835$ \\
\hline Education, n(\%) & & & & ${ }^{\ni} 0.052$ \\
\hline $0-12$ years & $156(60.7)$ & $91(56.2)$ & $65(68.4)$ & \\
\hline $12+$ years & $101(39.3)$ & $71(43.8)$ & $30(31.6)$ & \\
\hline Marital Status, n(\%) & & & & э 0.943 \\
\hline Married/Defacto & $194(75.8)$ & $123(75.9)$ & $71(75.5)$ & \\
\hline Single/Divorced & $62(24.2)$ & $39(24.1)$ & $23(24.5)$ & \\
\hline Physical Activity & & & & ${ }^{\ni} 0.940$ \\
\hline Rarely & $45(17.5)$ & $28(17.3)$ & $17(17.8)$ & \\
\hline Sometimes & $101(33.3)$ & $65(40.1)$ & $36(37.9)$ & \\
\hline Often & $111(43.2)$ & $69(42.6)$ & $42(44.2)$ & \\
\hline Daily Hassles Severity & $6.7(4.1)$ & $6.4(9.2)$ & $7.1(9.7)$ & $\wedge 0.540$ \\
\hline Bothersome Symptoms Frequency & $7.3(3.9)$ & $7.1(3.9)$ & $7.7(3.9)$ & $\wedge 0.257$ \\
\hline Attitude Towards Ageing & $23.1(2)$. & $23.3(2.5)$ & $22.9(2.4)$ & $\wedge 0.183$ \\
\hline Attitude Towards Menopause & $24.4(3.3)$ & $24.6(3.3)$ & $24(3.3)$ & $\wedge 0.197$ \\
\hline Work Status n(\%) & & & & ${ }^{\ni} 0.171$ \\
\hline Not employed & $124(49.2)$ & $73(46)$ & $51(54.8)$ & \\
\hline Employed & $128(50.8)$ & $86(54.1)$ & $42(45.2)$ & \\
\hline Self-Rated Health Status n(\%) & & & & ${ }^{\ni} 0.402$ \\
\hline 'Same or worse than most' & $160(62.3)$ & $104(65.2)$ & $56(35)$ & \\
\hline 'Better than most' & $97(37.7)$ & $58(59.8)$ & $39(40.2)$ & \\
\hline Smoking Status, n(\%) & & & & э 0.406 \\
\hline Smoker & $21(8.2)$ & $15(9.3)$ & $6(6.3)$ & \\
\hline Non-smoker & $236(91.8)$ & $147(90.7)$ & $89(93.7)$ & \\
\hline BMI & $27.5(5.6)$ & $28(5.62)$ & $26.6(5.4)$ & $\wedge 0.052$ \\
\hline
\end{tabular}

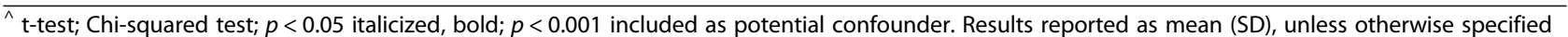

Table 4 Multivariate Analysis of 2002 variables and 2012 CESD scores

\begin{tabular}{lll}
\hline Variable (2002) & Beta $(95 \% \mathrm{Cl})$ & $p$-value \\
\hline Age & $0.04(-0.02,0.09)$ & 0.173 \\
Positive Mood Score & $-0.45(-0.76,-0.15)$ & $\mathbf{0 . 0 0 4}$ \\
BMI & $0.01(-0.01,0.04)$ & 0.338 \\
Attitude Toward Ageing & $-0.01(-0.09,0.07)$ & 0.801 \\
Attitude Toward Menopause & $0.02(-0.04,0.08)$ & 0.477 \\
Daily Hassles Severity & $0.01(-0.00,0.03)$ & 0.227 \\
Bothersome Symptoms Frequency & $0.01(-0.03,0.05)$ & 0.702 \\
\hline
\end{tabular}

Cl Confidence Intervals; bold, italicised - significant; Gamma regression was used to derive estimates; All models were adjusted for education, work status, positive affect, marital status and self-rated health correlation between 2012 CESD scores and the following variables assessed in 1992: current smoking status (6 (310) vs $4(2-7)$ for non-smokers, $p=0.023)$; negative $\operatorname{mood}($ rho $=0.3, p=<001)$; positive $\operatorname{mood}($ rho $=-0.3$, $p<0.001$ ); wellbeing score (rho $=-0.3, p<0.001$ ); number of bothersome symptoms (rho $=0.3, p=<0.001$ ) and number of daily hassles (rho $=0.3, p<0.001)$. See Appendix 3 in Table 9 for a summary of these analyses.

However, Daily Hassle severity and positive mood remained the only predictors of CESD 20 years later, while controlling for potential confounders as demonstrated in Table 6.

The results of the analysis indicated that lower scores on the positive mood scale and higher Daily Hassles 
Table 5 Comparison of 1992 variables for participants who dropped out between 1992 and 2012, and the WHAP cohort remaining in 2012, with signficiant differences between retention cohorts bolded

\begin{tabular}{|c|c|c|c|c|}
\hline & 1992 Cohort & Included in 2012 follow-up assessment & Did not have follow-up data 2012 & $p$-value \\
\hline Sample Size & 438 & 220 & 218 & \\
\hline Age Mean (SD) & $49.6(2.5)$ & $49.63(2.53)$ & $49.5(2.4)$ & $\wedge 0.494$ \\
\hline \multicolumn{5}{|l|}{ Affectometer Score } \\
\hline Negative Mood Score Mean (SD) & $0.5(0.4)$ & $0.44(0.35)$ & $0.5(0.4)$ & $\wedge 0.029$ \\
\hline Positive Mood Score Mean (SD) & $2.18(0.6)$ & $2.18(0.60)$ & $2.2(0.6)$ & $\wedge 0.401$ \\
\hline Wellbeing Score Mean (SD) & $1.73(0.9)$ & $1.74(0.87)$ & $1.7(0.9)$ & $\wedge 0.700$ \\
\hline \multicolumn{5}{|l|}{ Education } \\
\hline $0-12$ years & $282(60)$ & 129(58.6) & $153(70.2)$ & ${ }^{*} 0.012$ \\
\hline $12+$ years & $156(33.2)$ & $91(41.4)$ & $65(29.8)$ & \\
\hline \multicolumn{5}{|l|}{ Marital Status } \\
\hline Married/Defacto & $351(74.7)$ & $179(81.4)$ & $172(79.3)$ & * 0.581 \\
\hline Single/Divorced & $86(18.3)$ & $45(20.7)$ & $45(20.7)$ & \\
\hline Daily Hassles Severity Mean (SD) & $6(8.24)$ & $5.4(6.7)$ & $6.6(9.5)$ & $\wedge 0.012$ \\
\hline Bothersome Symptoms Frequency Mean (SD) & $5.8(3.8)$ & $5.8(3.8)$ & $5.9(3.9)$ & $\wedge 0.504$ \\
\hline Attitude Towards Ageing Mean (SD) & $17.16(2.67)$ & $15.4(2)$ & $15.4(2.1)$ & $\wedge 0.492$ \\
\hline Attitude Towards Menopause Mean (SD) & $18(1.95)$ & $18.5(2.2)$ & $18.2(2.3)$ & $\wedge 0.295$ \\
\hline Number of Premenstrual Complaints Mean (SD) & $2.3(2.6)$ & $1.92(1.4)$ & $2.57(3.3)$ & $\wedge 0.041$ \\
\hline Self-Reported Physical Disease Current n (valid \%) & $82(17.4)$ & $45(20.5)$ & $37(17.1)$ & ${ }^{\ni} 0.362$ \\
\hline \multicolumn{5}{|l|}{ Work Status n (valid \%) } \\
\hline Not employed & $106(22.6)$ & $48(21.8)$ & $58(26.9)$ & ${ }^{\ni} 0.221$ \\
\hline Employed & $330(70.2)$ & $172(78.2)$ & $158(73.1)$ & \\
\hline Self-Rated Health Status $n$ (valid \%) & & & & ${ }^{\ni} 0.013$ \\
\hline 'Same or worse than most' & $211(49.4)$ & $102(48.3)$ & $109(51.7)$ & \\
\hline 'Better than most' & $216(50.6)$ & $113(52.3)$ & $103(47.7)$ & \\
\hline Physical Activity & & & & ${ }^{\ni} 0.089$ \\
\hline Rarely & $127(30)$ & $71(32.3)$ & $56(27.5)$ & \\
\hline Sometimes & $155(36.6)$ & $86(39.1)$ & $69(33.8)$ & \\
\hline Often & $142(33.5)$ & $63(28.6)$ & 79 (38.7) & \\
\hline \multicolumn{5}{|l|}{ Smoking Status } \\
\hline Smoker & $90(19.1)$ & $37(16.8)$ & $53(24.4)$ & ${ }^{\ni} 0.049$ \\
\hline Non-smoker & $347(73.8)$ & $183(83.2)$ & $164(75.6)$ & \\
\hline BMI Mean (SD) & $25.9(4.9)$ & $26(4.7)$ & $25.8(5.2)$ & $\wedge 0.100$ \\
\hline Alcohol User n (valid \%) & $282(60)$ & $149(67.7)$ & $133(61.3)$ & ${ }^{\ni} 0.160$ \\
\hline
\end{tabular}

${ }^{\wedge}$ t-test; Chi-squared test; ${ }^{*}$ Chi-squared test with Fishers' Exact Test; $p<0.05$ italicized and bolded; $p<0.001$ included as potential confounder

severity in 1992 were statistically significant predictors of higher CESD scores a decade later in 2012. An increase in Daily Hassles severity score resulted in a 0.18 increase in CESD scores $(p=0.004)$. A higher positive mood score resulted in a 1.55 decrease in CESD total severity $(p=0.009)$.

\section{Discussion}

In this study certain risk factors identified at different age ranges were shown to be more consistently associated with higher reporting of depressive symptoms for women as they transitioned across the midlife and into early late life, age 65 to 77, representing potential specialised targets for early assessment and intervention. Low positive mood scores reported when women were aged 50 and 60 years were associated with higher levels of depressive symptom scores when they were aged 70 years, suggesting that low positive mood may be a consistent midlife risk factor for depressed mood in early late life. Positive mood was more strongly associated 
Table 6 Multivariate analysis of 2002 variables and 2012 CESD scores

\begin{tabular}{lll}
\hline Variable (2002) & Beta $(95 \% \mathrm{Cl})$ & $p$-value \\
\hline Age & $0.05(-0.00,0.09)$ & 0.053 \\
Positive Mood Score & $-0.29(-0.50,-0.08)$ & $\mathbf{0 . 0 0 7}$ \\
BMI & $0.01(-0.01,0.04)$ & 0.316 \\
Attitude Toward Ageing & $-0.01(-0.07,0.05)$ & 0.669 \\
Attitude Toward Menopause & $0.02(-0.03,0.07)$ & 0.365 \\
Daily Hassles Severity & $0.03(-0.01,0.05)$ & $\mathbf{0 . 0 0 2}$ \\
Bothersome Symptoms Frequency & $0.01(-0.03,0.05)$ & 0.662
\end{tabular}

Cl Confidence Intervals; bold, italicised - significant; Gamma regression was used to derive estimates; All models were adjusted for education, work status, positive affect, marital status and self-rated health

with the presence of depressive symptoms than negative mood at ages 50 years and 60 years. Other factors experienced at certain age ranges may also have a long-lasting effect on the risk of depressive symptoms. The number of daily hassles which represents higher experience of chronic stress, reported by women at mean age 50 years, but not 60 years, was associated with higher depressive symptoms at mean age 70 . Similarly, cross-sectional analysis conducted when women were at mean age of 70 years demonstrated that women who reported more bothersome symptoms or who had higher anxiety at the time of assessment were more likely to also report higher depressive symptom scores.

The influence of low positive affect on risk of depressive symptoms in this cohort is consistent with other longitudinal studies that have found that low positive affect predicts heightened levels of depression [29-32]. These longitudinal studies include both genders and varying age ranges, including assessment of children [32]. Characteristics associated with positive affect relate not only to happiness but also increased interest, energy and confidence [33]. It has been proposed that these positive characteristics reduce vulnerability to negative events by improving emotional wellbeing and capacity for coping with adversities [34]. It has also been demonstrated that positive mood and emotions broaden attention and cognition and promote flexibility and creative thinking [34]. Positive beliefs about relationship support and personal coping ability have been shown to moderate the effect of life events on suicidality [35]. Several interventions focused on improving Positive Emotionality (PE) have been developed, and preliminary evidence suggests that these types of interventions decrease symptoms amongst currently depressed and anxious individuals [31, 36]. Developing PE in midlife women may improve emotional resilience and reduce the risk of the onset or recurrence of depressive symptoms. Positive mood in midlife may have a longstanding impact on emotional resilience as women enter late life and the findings from this study suggest the need for further examination of positive affect as a long-term protective factor.

The impact of stress on depressive symptoms has been consistently documented, with early life stress being a well-established risk factor for depression [37]. The experience of a stressful life event across adulthood has been shown to be a consistent risk factor $[38,39]$. The findings of this study add further support to the potential long-term impact of self-reported chronic stress on depressive symptoms. The bidirectional relationship between stress and depressive symptoms longitudinally needs to be explored further. Those who report a greater level of chronic stress in midlife may have characteristics that make them more vulnerable to experiencing, or reacting more strongly to stressors, similarly to the way that depressogenic characteristics are thought to increase risk of experiencing depressive symptoms [40]. Further research examining the impact of midlife stress on late life depressive symptoms may be useful in identifying the role that chronic stress plays as an ongoing risk factor for increased vulnerability to depressive symptoms.

This study also demonstrated that women who had higher depressive scores at 70 years reported experiencing higher anxiety and more bothersome symptoms concurrently. Within the WHAP cohort a greater number of bothersome symptoms when women were mean age 50 years and 60 years were also identified as predictors for higher CESD-SF scores when women were 60 years old [7]. The presence of bothersome symptoms as a risk factors for women aged 50 years and 60 years may be attributable to different physical vulnerabilities. The final menstrual period occurs, on average, at the age of 51 years [41] and the physical symptoms associated with the early stages of the climacteric may have contributed to higher reports of bothersome symptoms at this time [1]. At mean age 60, physical health can begin to deteriorate, and ongoing physical symptoms associated with the postmenopause can remain. Hot flashes causing discomfort have been shown to be present up to 10 years following the final menstrual period [42]. The combination of these factors may increase the experience of bothersome symptoms at age 60 years.

The impact of physical health on the presence of higher depressive symptoms in late life is commonly reported, and chronic physical health problems have been demonstrated to be amongst the strongest predictors of depressed mood for women in old age [43]. The significant association between number of bothersome physical symptoms and presence of depressive symptoms in this 
cohort at age 70 years is consistent with findings that chronic disease, decreases in functioning, and chronic pain are all associated with higher rates of depression in older cohorts [44]. The presence and severity of bothersome symptoms appears to be a consistent risk factor for higher ratings of depressive symptom scores in the WHAP cohort, being associated with higher scores at 50 years, 60 years and 70 years [7]. The measure of bothersome symptoms used in this study was developed based on frequently reported physical symptoms associated with the menopause. The items represent general physical concerns associated with that stage of reproductive ageing and it is was an unexpected result to see the degree to which those same physical symptoms were present in the sample when they were 70 . The type of physical concerns experienced at menopause does not appear to be unique to that age range. A further analysis of the type of physical symptoms reported at the different age ranges across the mid-life to late life period would be useful to explore menopause specific physical symptoms compared to physical symptoms consistently experienced by women as part of the ageing process.

The association between depressive symptoms and higher anxiety levels demonstrated in this study during the late life period is consistent with research demonstrating comorbidity between these symptoms $[45,46]$. Co-occurrence of depression and anxiety has been demonstrated across the life cycle and is associated with a poorer prognosis. This results in greater functional disability and requires more service utilisation than a single disorder [45, 47]. Generalized anxiety and phobias are thought to be the most prevalent disorders in the elderly, and it has been proposed that standard screening for anxiety when depressive symptoms are present may be useful in older populations $[37,46]$. Our findings support this and indicate a decade lead time for intervention to reduce burden of disease.

This study utilised data from a group of women across a 20-year time period. While drop-outs were inevitable, the retention rates were relatively high. The longitudinal nature of the study lead to the introduction of new research questions and assessments which resulted in some changes in the way that responses were categorized over time. As a consequence, some variables had inconsistent categories of responses across time points, resulting in the need for broad categories to be used when examining the data across multiple time points. This allowed for general comparison across the two decades but the exact ranges of responses specific to each time point were unable to be utilised. Ideally, additional variables related to answering the current research goal would have been included at the onset of the study, however the establishment of the study over 20 years ago meant that certain relevant variables were not available. In this study clinical diagnosis of depression was not determined and conclusions can only be generalised in relation to depressive symptom scores in educated women from a Western population. The examination of depressive symptom ratings rather than clinical diagnosis in this cohort remains relevant as mild or moderate distress caused by sub-clinical symptoms can cause a significant amount of distress to older adults and needs to be acknowledged [48]. A strength of this study was the inclusion of an anxiety measure as the women aged, given the high occurrence of anxiety symptoms in older adults [46], but it would have been useful to have additional data specific to anxiety from an earlier time point.

Low positive mood scores had a higher association with later reporting of depressive symptoms than higher negative mood scores at both 50 and 60 years. Negative and positive affect have been shown to represent unique dimensions of mood state rather than representing inverse constructs [48, 49]. Future work exploring the strength of positive mood as a protective factor, as opposed to the influence of negative mood as a risk factor may provide an insight into the unique contributions of affect on depressive symptoms in early late life. Further work exploring the long-term impact of chronic stress in more detail may also help to clarify how this type of ongoing stress impacts coping and resilience.

\section{Conclusion}

The current analysis contributes to the understanding of the role of positive affect in association with depressive symptoms in a female cohort representing real world rates of morbidity with data spanning two decades. This work suggests that levels of positive mood in women during the midlife may be a protective factor for late life depressive symptoms and interventions aimed at enhancing positive affect should be explored further. In addition to consistent risk factors, age specific risk factors were also present. The findings from this analysis suggest that at age 50 , focusing on chronic stress may be the most helpful point of intervention, while at age 70 an emphasis should be placed on physical symptoms and anxiety. Regardless of the reason for the presence of bothersome symptoms, the severity of these physical symptoms is consistently associated with higher reports of depressive symptoms as women transition from midlife to late life. It may be useful for clinicians to consistently monitor bothersome physical symptoms as a risk factor for depressive symptoms in adult women as they age. Further work would be needed to identify if these age-specific, and consistent, risk factors are evident in other longitudinal cohorts of similar duration. 


\section{Appendix 1}

Table 7 Cross-Sectional Association between CESD, lifestyle and health variables in 2012

\begin{tabular}{lccc}
\hline Variable & rho & CESD Median (IQR) & $p$-value \\
\hline Age & 0.1 & ${ }^{\ni} 0.107$
\end{tabular}

Affectometer Score

$\begin{array}{lll}\text { Negative Mood Score } & 0.6 & { }^{\ni} \mathbf{0 . 0 0 0} \\ \text { Positive Mood Score } & -0.5 & { }^{\ni} \mathbf{0 . 0 0 0} \\ \text { Wellbeing Score } & 0.6 & { }^{\ni} \mathbf{0 . 0 0 0} \\ \text { Geriatric Depression Scale } & 0.6 & { }^{\ni} \mathbf{0 . 0 0 0}\end{array}$

Hospital Anxiety Stress Scale

Anxiety Subscale

Depression Subscale

0.6

Daily Hassles Severity

Bothersome Symptoms Frequency 0.5

BMI

0.1

Education

$0-12$ years
$12+$ years
Marital Status

Marital Status

$$
\begin{aligned}
& \text { Married/Defacto } \\
& \text { Single/Divorced }
\end{aligned}
$$

Physical Activity

Rarely
Sometime
Often

Work Status

Not employed

Employed

Self-Rated Health Status

'Same as/worse than most'

'Better than most'

$5(2-8)$

$4(2-7)$

5(4-7)

4(2-7.5)

$6.1(2-9)$

$4.64(2-7)$

$4.97(2-7)$

5(2-8)

$4(1-7)$

$6(2.5-9)$

$4(1.5-6)$

Smoking Status

Smoker

Non-smoker

${ }^{{ }}$Spearman Correlation; ${ }^{\alpha}$ Mann-Whitney Test; $\wedge$ Kruskall-Wallis Test; $p<0.05$ italicized; $p<0.001$ included as potential confounder

${ }^{\ni} 0.000$

${ }^{\ni} 0.000$

${ }^{\ni} 0.000$

${ }^{\ni} 0.000$

${ }^{\ni} 0.000$

${ }^{\wedge} 0.446$

${ }^{\wedge} 0.039$

${ }^{\alpha} 0.014$

\section{Appendix 2}

Table 8 Associations between 2002 mid-life demographic and clinical factors, and late life CESD scores

\begin{tabular}{llll}
\hline Variable (2002) & rho & CESD (2012) & $p$-value \\
& Median (IQR) \\
\hline
\end{tabular}

Age

Affectometer Score

Negative Mood Score $\quad 0.3$

Positive Mood Score $\quad-0.4$

Wellbeing Score $\quad 0.4$

${ }^{\ni} 0.111$

CESD-Brief

0.3

0.000

BMI

0.1

0.000

$-0.4$

${ }^{\ni} 0.000$

${ }^{\ni} 0.000$

Daily Hassles Severity

Bothersome Symptoms Frequency

0.3

${ }^{\ni} 0.318$

Attitude Towards Ageing

0.3

${ }^{\ni} 0.000$

Attitude Towards Menopause $\quad-0.1$

${ }^{\ni} 0.001$

${ }^{{ }^{\circ}} 0.431$

Education

${ }^{\ni} 0.091$

$$
\begin{aligned}
& 0-12 \text { years } \\
& 12+\text { years }
\end{aligned}
$$

${ }^{\alpha} 0.637$

$4.4(2-7.5)$

$5(2-7)$

Physical Activity

Rarely

Sometimes

Often

${ }^{\propto} 0.096$

Work Status

Not employed

Employed

${ }^{\propto} 0.050$

Self-Rated Health Status

'Same as/worse than most' $\quad$ 5.5(3-8)

$6.8(4-8)$

$5(2-7)$

$4.9(2-7)$

4(2-7)

5(2-9)

'Better than most'

${ }^{\alpha} 0.169$

Smoking Status

$4(2-7)$

Smoker

Non-smoker

6(3-9)

$4(2-7)$

Marital Status

Married/Defacto

$4(2-7)$

Single/Divorced

5.5(3.5-7)

${ }^{\ni}$ Spearman Correlation; ${ }^{\alpha}$ Mann-Whitney Test; $\wedge$ Kruskall-Wallis Test; $p<0.05$ italicized; $p<0.001$ included as potential confounder 
Table 9 Associations between mid-life demographic and clinical factors in 1992, and late life CESD scores assessed in 2012

\begin{tabular}{|c|c|c|c|}
\hline Variable (1992) & rho & $\begin{array}{l}\text { CESD (2012) } \\
\text { Median (IQR) }\end{array}$ & $p$-value \\
\hline Age & 0.1 & & ${ }^{\ni} 0.089$ \\
\hline \multicolumn{4}{|l|}{ Affectometer Score } \\
\hline Negative Mood Score & 0.3 & & ${ }^{\ni} 0.000$ \\
\hline Positive Mood Score & -0.3 & & ${ }^{\ni} 0.000$ \\
\hline Wellbeing Score & -0.4 & & ${ }^{\ni} 0.000$ \\
\hline BMI & 0.1 & & ${ }^{\ni} 0.162$ \\
\hline Daily Hassles Severity & 0.3 & & ${ }^{\ni} 0.000$ \\
\hline Bothersome Symptoms Frequency & 0.3 & & ${ }^{\ni} 0.000$ \\
\hline Attitude Towards Ageing & -0.1 & & ${ }^{\ni} 0.187$ \\
\hline Attitude Towards Menopause & -0.1 & & ${ }^{\ni} 0.364$ \\
\hline Number of Premenstrual Complaints & 0.0 & & ${ }^{\ni} 0.885$ \\
\hline Self-Reported Physical Disease Current & & & ${ }^{\ni} 0.093$ \\
\hline None reported & & $4(2-7)$ & \\
\hline Physical Disease Reported & & $6(3-8)$ & \\
\hline Education & & & ${ }^{\propto} 0.938$ \\
\hline $0-12$ years & & $4.9(2-8)$ & \\
\hline $12+$ years & & $4(2-7)$ & \\
\hline Physical Activity & & & $\wedge 0.350$ \\
\hline Rarely & & $5.8(2-8)$ & \\
\hline Sometimes & & $4.9(2-7)$ & \\
\hline Often & & $4.8(1-7)$ & \\
\hline Work Status & & & ${ }^{\propto} 0.559$ \\
\hline Not employed & & $5(3-8)$ & \\
\hline Employed & & $4(2-7.5)$ & \\
\hline Self-Rated Health Status & & & ${ }^{\propto} 0.843$ \\
\hline 'Same as/worse than most' & & $4(2-8)$ & \\
\hline 'Better than most' & & $4.8(2-7)$ & \\
\hline Smoking Status & & & ${ }^{\propto} 0.023$ \\
\hline Smoker & & $6(3.5-10)$ & \\
\hline Non-smoker & & $4(2-7)$ & \\
\hline Alcohol Use in Last Week & & & ${ }^{\propto} 0.655$ \\
\hline Yes & & $5(2-7)$ & \\
\hline No & & $4(2-9)$ & \\
\hline Marital Status & & & ${ }^{\wedge} 0.247$ \\
\hline Married/Defacto & & $4(2-8)$ & \\
\hline Single/Divorced & & $5(3-7)$ & \\
\hline
\end{tabular}

${ }^{\ni}$ Spearman Correlation; ${ }^{\alpha}$ Mann-Whitney Test; $\wedge$ Kruskall Wallis Test; $p<0.05$ italicized; $p<0.001$ included as potential confounder

\section{Acknowledgements}

We would like to acknowledge the contribution of the participants and their supporters for their time and commitment for over 20 years to the University. We thank BioGrid for providing data linkage, Melbourne Health Pathology services for providing blood biomarker storage and analyses. We thank the research assistants who assisted in data collection. A full list of all researchers contributing to the project and the membership of our Scientific Advisory Board is available at http://www.medrmhwh.unimelb.edu.au/ Research/WHAP.html. We are thankful to our participants' team, partners and supporters for making this study of now more than 20 years possible.

\section{Authors' contributions}

KEC participated in the study design, data collection and interpretation, and created the initial draft of the manuscript. LD contributed to the study design and data collection and was involved in revising the manuscript. CES participated in the study design and data collection and assisted in revising the manuscript. AG contributed to the study design, assisted in the data analysis and was involved in revising the manuscript. All authors read and approved the final version.

\section{Funding}

Funding for the Healthy Ageing Program (HAP) has been provided by the National Health and Medical Research Council (NHMRC Grants 547600, 1032350 \& 1062133), Ramaciotti Foundation, Australian Healthy Ageing Organisation, the Brain Foundation, the Alzheimer's Association (NIA320312), Australian Menopausal Society, Bayer Healthcare, Shepherd Foundation, Scobie and Claire Mackinnon Foundation, Collier Trust Fund, J.O. \& J.R. Wicking Trust, Mason Foundation and the Alzheimer's Association of Australia and Royal Australian College of Physicians. Inaugural funding was provided by VicHealth and the NHMRC. The Principal Investigator of HAP (Cassandra Szoeke) is supported by the National Health and Medical Research Council.

\section{Availability of data and materials}

The datasets used and/or analysed during the current study are available (subject to consideration from the director of Women's Healthy Ageing Project) on reasonable request.

\section{Ethics approval and consent to participate}

This study was approved by the University of Melbourne Human Research Ethics Committee (HREC:931149X, 1034765, 1105251 \& 750632.1), and all participants provided written informed consent. Participants did not receive a stipend for participating in this study. The study was conducted in accordance with the National Health and Medical Council Ethical Conduct in Human Research and Declaration of Helsinki. Authors' disclosures available online (https://www.j-alz.com/manuscript-disclosures/18-0815r1). All women have provided written consent for each time point in which they have participated.

\section{Consent for publication}

Not applicable.

\section{Competing interests}

KEC, LD and AG report no conflict of interest. CS has provided clinical consultancy and been on scientific advisory committees for the Australian Commonwealth Scientific and Industrial Research Organisation, Alzheimer's Australia, University of Melbourne and other relationships which are subject to confidentiality clauses. She has been a named Chief Investigator on investigator driven collaborative research projects in partnership with Pfizer, Merck, Bayer and GE. She has been an investigator on clinical trials with Lundbeck within the last 2 years. The Healthy Ageing Program has received support from National Health and Medical Research Council, Alzheimer's Association, Collier Trust, Scobie and Claire Mackinnon Foundation, JO and JR Wicking Trust, Shepherd Foundation, Brain Foundation, Mason Foundation, Ramaciotti Foundation, Alzheimer's Australia, and The Royal Australian College of Physicians. She may accrue revenues from patent in pharmacogenomics prediction of seizure recurrence.

\section{Author details}

${ }^{1}$ School of Psychology, Charles Sturt University, Bathurst, New South Wales, Australia. ${ }^{2}$ Department of Medicine (RMH), University of Melbourne, 
Melbourne, Victoria, Australia. ${ }^{3}$ School of Behavioural and Health Science, Australian Catholic University, Melbourne, Victoria, Australia. ${ }^{4}$ Department of Psychiatry, University of Melbourne, Melbourne, Victoria, Australia.

Received: 2 July 2019 Accepted: 17 February 2020 Published online: 04 March 2020

\section{References}

1. Harlow SD, Gass M, Hall JE, Lobo R, Maki P, Rebar RW, et al. Executive summary of the stages of reproductive aging workshop+ 10: addressing the unfinished agenda of staging reproductive aging. Climacteric. 2012;15(2):105-14.

2. Freeman EW. Associations of depression with the transition to menopause. Menopause. 2010;17(4):823-7

3. Vesco KK, Haney EM, Humphrey L, Fu R, Nelson HD. Influence of menopause on mood: a systematic review of cohort studies. Climacteric. 2007;10(6):448-65

4. Frey BN, Lord C, Soares CN. Depression during menopausal transition: a review of treatment strategies and pathophysiological correlates. Menopause Int. 2008;14(3):123-8.

5. Soares CN. Mood disorders in midlife women: understanding the critical window and its clinical implications. Menopause. 2014;21(2):198-206.

6. Kuehner C. Why is depression more common among women than among men? Lancet Psychiatry. 2017:4(2):146-58.

7. Dennerstein L, Guthrie J, Clark M, Lehert P, Henderson V. A populationbased study of depressed mood in middle-aged, Australian-born women. Menopause. 2004;11(5):563-8.

8. Bromberger J, Schott L, Kravitz H, Joffe H. Risk factors for major depression during midlife among a community sample of women with and without prior major depression: are they the same or different? Psychol Med. 2015 45(8):1653-64.

9. Dugan SA, Bromberger JT, Segawa E, Avery E, Sternfeld B. Association between physical activity and depressive symptoms: midlife women in SWAN. Med Sci Sports Exerc. 2015:47(2):335-42.

10. Freeman EW, Sammel MD, Lin H, Gracia CR, Pien GW, Nelson DB, et al. Symptoms associated with menopausal transition and reproductive hormones in midlife women. Obstet Gynecol. 2007;110(2, Part 1):230.

11. Freeman EW, Sammel MD, Lin H, Nelson DB. Associations of hormones and menopausal status with depressed mood in women with no history of depression. Arch Gen Psychiatry. 2006;63(4):375-82.

12. Mitchell ES, Woods NF. Depressed mood during the menopausal transition: is it reproductive aging or is it life? Women's Midlife Health. 2017:3(1):11

13. Blazer DG. Depression in late life: review and commentary. J Gerontol Series A: Bio Sci Med Sci. 2003;58(3):M249-65.

14. Szoeke C, Coulson M, Campbell S, Dennerstein L. Cohort profile: Women's healthy ageing project (WHAP)-a longitudinal prospective study of Australian women since 1990. Women's Midlife Health. 2016:4(2):5.

15. Dennerstein $L$, Lehert $P$, Guthrie J. The effects of the menopausal transition and biopsychosocial factors on well-being. Arch Women's Ment Health. 2002;5(1):15-22

16. Dennerstein $L$, Lehert $P$, Burger $H$, Dudley E. Mood and the menopausal transition. J Nerv Ment Dis. 1999;187(11):685-91.

17. Lewinsohn PM, Seeley JR, Roberts RE, Allen NB. Center for Epidemiologic Studies Depression Scale (CES-D) as a screening instrument for depression among community-residing older adults. Psychol Aging. 1997;12(2):277-87

18. Smarr KL, Keefer AL. Measures of depression and depressive symptoms: Beck depression inventory-II (BDI-II), Center for Epidemiologic Studies Depression Scale (CES-D), geriatric depression scale (GDS), hospital anxiety and depression scale (HADS), and patient health Questionnaire-9 (PHQ-9). Arthritis Care Res. 2011:63(S11):S454-S66.

19. Kohout FJ, Berkman LF, Evans DA, Cornoni-Huntley J. Two shorter forms of the CES-D depression symptoms index. J Aging Health. 1993;5(2):179-93.

20. Zigmond AS. And R Snaith. The hospital anxiety and depression scale. Acta Psychiatr Scand. 1983;67(6):361-70.

21. Bjelland I, Dahl AA, Haug TT, Neckelmann D. The validity of the hospital anxiety and depression scale: an updated literature review. J Psychosom Res. 2002;52(2):69-77.

22. Dennerstein L, Dudley E, Burger H. Well-being and the menopausal transition. J Psychosom Obstet Gynecol. 1997;18(2):95-101.

23. Kanner AD, Coyne JC, Schaefer C, Lazarus RS. Comparison of two modes of stress measurement: daily hassles and uplifts versus major life events. J Beh Med. 1981;4(1):1-39.
24. Dennerstein L, Smith A, Morse C. Psychological well-being, mid-life and the menopause. Maturitas. 1994;20(1):1-11.

25. Kaufert P, Syrotuik J. Symptom reporting at the menopause. Soc Sci Med E. 1981;15(3):173-84

26. Avis NE, Brambilla DJ, Vass K, McKinlay JB. The effect of widowhood on health: a prospective analysis from the Massachusetts Women's health study. Soc Sci Med. 1991;33(9):1063-70.

27. Dennerstein L, Dudley EC, Hopper JL, Guthrie JR, Burger HG. A prospective population-based study of menopausal symptoms. Obstet Gynecol. 2000; 96(3):351-8.

28. Szoeke CE, Robertson JS, Rowe CC, Yates P, Campbell K, Masters CL, et al. The Women's healthy ageing project: fertile ground for investigation of healthy participants 'at risk' for dementia. Int Rev Psychiatry. 2013;25(6):726-37.

29. Corp IBM. IBM SPSS statistics for windows, version 21.0. Armonk: IBM Corp: 2012

30. StataCorp. In: Station C, editor. Stata Statistical Software: Release 13. TX: StatCorp LP; 2013

31. Kasch KL, Rottenberg J, Arnow BA, Gotlib IH. Behavioral activation and inhibition systems and the severity and course of depression. J Abnorm Psychol. 2002;111(4):589-97.

32. Naragon-Gainey K, Gallagher MW, Brown TA. Stable "trait" variance of temperament as a predictor of the temporal course of depression and social phobia. J Abnorm Psychol. 2013;122(3):611-23.

33. Khazanov GK, Ruscio AM. Is low positive emotionality a specific risk factor for depression? A meta-analysis of longitudinal studies. Psychol Bull. 2016; 142(9):991.

34. Dougherty LR, Klein DN, Durbin CE, Hayden EP, Olino TM. Temperamental positive and negative emotionality and children's depressive symptoms: a longitudinal prospective study from age three to age ten. J Soc Clin Psychol. 2010;29(4):462-88.

35. Watson D, Naragon-Gainey K. On the specificity of positive emotional dysfunction in psychopathology: evidence from the mood and anxiety disorders and schizophrenia/schizotypy. Clin Psychol Rev. 2010;30(7):839-48.

36. Fredrickson $\mathrm{BL}$, Joiner T. Positive emotions trigger upward spirals toward emotional well-being. Psychol Sci. 2002;13(2):172-5.

37. Johnson J, Gooding PA, Wood AM, Taylor PJ, Pratt D, Tarrier N. Resilience to suicidal ideation in psychosis: positive self-appraisals buffer the impact of hopelessness. Behav Res Ther. 2010;48(9):883-9.

38. McMakin DL, Siegle GJ, Shirk SR. Positive affect stimulation and sustainment (PASS) module for depressed mood: a preliminary investigation of treatment-related effects. Cognit Ther Res. 2011;35(3):217-26.

39. Heim C, Binder EB. Current research trends in early life stress and depression: review of human studies on sensitive periods, geneenvironment interactions, and epigenetics. Exp Neurol. 2012;233(1):102-11.

40. Kendler KS, Gardner CO. Dependent stressful life events and prior depressive episodes in the prediction of major depression: the problem of causal inference in psychiatric epidemiology. Arch Gen Psychiatry. 2010; 67(11):1120-7.

41. Kendler KS, Kessler RC, Walters EE, MacLean C, Neale MC, Heath AC, Eaves LJ. Stressful life events, genetic liability, and onset of an episode of major depression in women. Focus. 2010:8(3):459-70.

42. Liu RT, Alloy LB. Stress generation in depression: a systematic review of the empirical literature and recommendations for future study. Clin Psychol Rev. 2010;30(5):582-93.

43. Forman MR, Mangini LD, Thelus-Jean R, Hayward MD. Life-course origins of the ages at menarche and menopause. Adolesc Health Med Ther. 2013:4:121.

44. Freeman EW, Sammel MD, Lin H. Temporal associations of hot flashes and depression in the transition to menopause. Menopause. 2009;16(4):728-34.

45. Penninx B. Women's ageing and depression. In: Keyes CL, Goodman SH, editors. Women and depression: a handbook for the social, behavioral, and biomedical sciences. New York: Cambridge University Press; 2006. p. 129-44.

46. Haralambous B, Lin X, Dow B, Jones C, Tinney J, Bryant C. Depression in older age: a scoping study: National Ageing Research Institute, a report for beyondblue; 2009

47. Schoevers R, Beekman A, Deeg D, Jonker C, Tilburg W. Comorbidity and risk-patterns of depression, generalised anxiety disorder and mixed anxietydepression in later life: results from the AMSTEL study. Int J Geriatr Psychiatry. 2003;18(11):994-1001.

48. Alexandrino-Silva C, Alves TF, Tofoli LF, Wang YP, Andrade LH. Psychiatry: life events and social support in late life depression. Clinics. 2011;66(2):233-8. 
49. Watson D, Clark LA, Tellegen A. Development and validation of brief measures of positive and negative affect: the PANAS scales. J Pers Soc Psychol. 1988;54(6):1063-70.

\section{Publisher's Note}

Springer Nature remains neutral with regard to jurisdictional claims in published maps and institutional affiliations.

Ready to submit your research? Choose BMC and benefit from:

- fast, convenient online submission

- thorough peer review by experienced researchers in your field

- rapid publication on acceptance

- support for research data, including large and complex data types

- gold Open Access which fosters wider collaboration and increased citations

- maximum visibility for your research: over $100 \mathrm{M}$ website views per year

At $\mathrm{BMC}$, research is always in progress. 